\title{
Alternative Analytical Method for Metal Determination in Inorganic Fertilizers Based on Ultrasound-Assisted Extraction
}

\author{
Alexandre F. Lima, Eduardo M. Richter and Rodrigo A. A. Muñoz* \\ Instituto de Química, Universidade Federal de Uberlândia, Av. João Naves de Ávila 2121, \\ Bloco 1D, 38400-902 Uberlândia-MG, Brazil
}

\begin{abstract}
Neste trabalho, o desenvolvimento de um método limpo de preparo de amostras para a análise de fertilizantes inorgânicos baseado em extração assistida por ultrassom usando um banho de ultrassom é descrito. Amostras (70 mg) foram sonicadas por $5 \mathrm{~min}$ na presença de $2 \mathrm{~mL}$ de $\mathrm{HNO}_{3} 50 \%$ (v/v) dentro de tubos de vidro. A determinação de cobre, chumbo e cádmio nos extratos foi realizada empregando espectrometria de absorção atômica com chama (FAAS). É também demonstrada a possibilidade de empregar um agitador vortex como fonte de agitação mecânica para realizar a extração dos metais. O método proposto usando banho de ultrassom ou agitador vortex é simples, versátil e minimiza a geração de resíduos devido ao emprego de volumes reduzidos de ácido e amostra, contribuindo para o desenvolvimento de um método analítico limpo.
\end{abstract}

In this work, the development of a "green" sample preparation procedure for the analysis of inorganic fertilizers based on ultrasound-assisted extraction using an ultrasonic bath is described. Samples (70 mg) were sonicated for $5 \mathrm{~min}$ in the presence of $2 \mathrm{~mL}$ of $50 \%(\mathrm{v} / \mathrm{v}) \mathrm{HNO}_{3}$ inside glass tubes. The determination of copper, lead and cadmium in the extracts were carried out by flame atomic absorption spectrometry (FAAS). It is also demonstrated the possibility of using of a vortex shaker as a mechanical agitation source to perform the metal extraction. The proposed extraction procedure using an ultrasonic bath or a vortex shaker is simple and versatile, and minimizes waste generation due to the employment of reduced volumes of acid and sample, contributing for the development of a clean analytical method.

Keywords: fertilizer, ultrasound, vortex, metals, extraction

\section{Introduction}

Inorganic fertilizers are a major source of metals in agricultural soils. Special attention is given to metals such as cadmium and lead due to their high toxicity. These metals can be absorbed by plants in agricultural lands and can reach the aquatic ecosystem health. Through rivers and streams, the metals are transported in suspended sediments or as dissolved species in water. The most deleterious effects of metal pollution in the aquatic environment are caused by the presence of dissolved metal species in water. ${ }^{1}$

In this way, the quality control of fertilizers is of capital importance to prevent environmental pollution by metals. The official method established by the Brazilian Ministry of Agriculture (Ministério de Agricultura, Pecuária e Abastecimento, MAPA) for the analysis of inorganic fertilizers involves a sample preparation step prior to atomic

*e-mail: raamunoz@iqufu.ufu.br absorption spectrometric determinations of metals. ${ }^{2}$ The sample preparation procedure consists of wet digestion with concentrated hydrochloric $(10 \mathrm{~mL})$ and nitric $(2.5 \mathrm{~mL})$ acids in hot plate in order to release the analytes from the sample matrix. ${ }^{2}$ The procedure takes around $40 \mathrm{~min}$ and employs large volumes of acids and sample, and consequently generates large amount of chemical waste in a routine laboratory. Moreover, the procedure is not adequate for the determination of volatile species such as arsenic and mercury due to losses via volatilization.

Sample preparation plays a key role in determining the success of subsequent analysis. Traditional digestion procedures are time-consuming and vulnerable to external contamination and losses of volatile elements. ${ }^{3}$ Microwaveassisted methods for sample preparation have been developed in order to overcome such drawbacks..$^{4-7}$ More recently, ultrasound-assisted (US-assisted) methods for sample preparation have been reported mainly using ultrasonic baths for the development of faster and less expensive procedures, 
operating at room-temperature and atmospheric-pressure and reducing the use of concentrated acids and large sample amounts, ${ }^{8-12}$ and hence contribute to the achievement of the "green" principles of analytical chemistry. ${ }^{13}$

In this work, the development of an alternative sample preparation procedure for the analyses of inorganic fertilizers based on the US-assisted extraction using ultrasonic bath is described. Samples were sonicated for $5 \mathrm{~min}$ in the presence of $2 \mathrm{~mL}$ of an acid solution $(50 \% \mathrm{v} / \mathrm{v})$ inside of glass tubes. Under the same conditions, the metal extraction with the agitation of a vortex shaker was performed. The determination of copper, lead and cadmium in the extracts were carried out by flame atomic absorption spectrometry (FAAS). For comparison, the samples were analyzed using the official method of analysis of inorganic fertilizers established by the Brazilian Ministry of Agriculture.

\section{Experimental}

\section{Reagents, samples and materials}

All solutions were prepared with deionized water (Gehaka-Master-System, Model OS 20LX) with a resistivity no less than $18 \mathrm{M} \Omega \mathrm{cm}^{-1}$. All laboratory glassware was washed with a neutral detergent, kept overnight in $10 \%(\mathrm{v} / \mathrm{v})$ nitric acid solution and finally rinsed with deionized water. Cadmium, copper and lead reference solutions were prepared from $1000 \mathrm{mg} \mathrm{L}^{-1}$ stock solutions (Titrisol ${ }^{\circledR}$, Merck, Darmstadt, Germany) in $0.3 \mathrm{~mol} \mathrm{~L}^{-1}$ $\mathrm{HNO}_{3}$. Analytical grade concentrated hydrochloric $(37 \% \mathrm{~m} / \mathrm{v})$ and nitric $(69 \% \mathrm{~m} / \mathrm{v})$ acids (Vetec, Rio de Janeiro, Brazil) were used without further purification. The extractions were performed in $15-\mathrm{mL}$ closed glass tubes.

Three commercial samples of inorganic fertilizers and two secondary reference samples identified as 13A (year 2009) and 41A (year 2009) provided by the interlaboratory program from National Association for the Promotion of Fertilizers (Associação Nacional para Difusão de Adubos, ANDA, Brazil) were analyzed. The three commercial samples are NPK-based fertilizers mixed with cuprite $\left(\mathrm{Cu}_{2} \mathrm{O}\right)$, in which $\mathrm{N}$ and $\mathrm{P}$ are originated from monoammonium phosphate (MAP) and $\mathrm{K}$ from $\mathrm{KCl}$. The two other inorganic fertilizers (reference samples) are a mixture of cuprite $\left(\mathrm{Cu}_{2} \mathrm{O}\right)$, pirolusite $\left(\mathrm{MnO}_{2}\right)$ and calamine $(\mathrm{ZnO})$.

\section{Instrumentation}

A Unique T50220 ultrasonic bath (São Paulo, Brazil) operating at $40 \mathrm{kHz}$ and $200 \mathrm{~W}$ was applied for the metal extractions. For comparison, a Phoenix AP56 vortex shaker (Araraquara, Brazil) working at $3800 \mathrm{rpm}$ was also used for the metal extractions (head for one single tube). A Fanem model 211 centrifuge (São Paulo, Brazil) with capacity for 4 tubes was used for centrifugation of the extracts. A GBC 932AA (Melbourne, Australia) flame atomic spectrophotometer (FAAS) equipped with the respective hollow cathode lamps was employed for the determination of $\mathrm{Cd}, \mathrm{Cu}$ and $\mathrm{Pb}$ in the extracts. The flow rate of air and acetylene were optimized using the diluted extracts. The instrument was operated under the recommended conditions of the manufacturer as shown in Table 1. The limits of detection (LOD) and of quantification (LOQ) were calculated in accordance to IUPAC $\left(\mathrm{LOD}=3 \mathrm{~s}_{\mathrm{B}} / \mathrm{S}\right.$ and $L O Q=10 s_{B} / S$, in which $s_{B}$ is the standard deviation of 10 consecutive measurements of the blank solution and $\mathrm{S}$ is the slope of the respective curves). The respective LOD and LOQ values for $\mathrm{Cd}, \mathrm{Cu}$ and $\mathrm{Pb}$ were 0.02, 0.09 and $0.06 \mathrm{mg} \mathrm{L}^{-1}$, and $0.07,0.30$ and $0.20 \mathrm{mg} \mathrm{L}^{-1}$, respectively.

Table 1. Operating parameters for the determination of cadmium, copper and lead by FAAS

\begin{tabular}{|c|c|c|c|}
\hline Instrumental parameters & $\mathrm{Cu}$ & $\mathrm{Pb}$ & $\mathrm{Cd}$ \\
\hline Wavelenght / nm & 327.4 & 217.0 & 228.8 \\
\hline Bandpass / nm & 0.5 & 1.0 & 0.5 \\
\hline Lamp current / mA & 8 & 6 & 3 \\
\hline Height of observation / $\mathrm{mm}$ & 7 & 7 & 7 \\
\hline Air flow rate / $\left(\mathrm{L} \mathrm{min}^{-1}\right)$ & 10 & 10 & 10 \\
\hline Acetylene flow rate / $\left(\mathrm{L} \mathrm{min}{ }^{-1}\right)$ & 2 & 2 & 2 \\
\hline Reading time / s & 1 & 1 & 1 \\
\hline Replicates & 3 & 3 & 3 \\
\hline Calibration curve / $\left(\mathrm{mg} \mathrm{L}^{-1}\right)$ & $10.0-40.0$ & $1.0-10.0$ & $0.1-4.0$ \\
\hline
\end{tabular}

\section{Extraction procedures}

Prior to the acid treatment (extraction or digestion), around $100 \mathrm{~g}$ of fertilizer samples were milled and sieved using a 35 mesh sieve (which corresponds to $0.50 \mathrm{~mm}$ sieve size).

Aqueous solutions of nitric and hydrochloric acids were evaluated as extractor solutions. Inside 15 -mL glass tubes, $70 \mathrm{mg}$ of sample was treated with $2 \mathrm{~mL}$ of the acid solution. The tubes were placed simultaneously inside the ultrasonic bath and sonicated for $5 \mathrm{~min}$. The tubes were placed over the ultrasound transducers (piezoelectric crystals), which are the regions with the most efficient ultrasound propagation as described in the literature. ${ }^{14,15}$ After US-extractions, the tubes were centrifuged and an appropriate aliquot of the extractor was taken and adequately diluted (from 250-fold to 0 -fold in accordance with the metal content in samples) 
with deionized water for further FAAS determinations. All procedure was performed at room temperature. This procedure was performed for the five analyzed samples in triplicate.

Similarly, the samples were treated with the acid solutions (as described for the US-assisted extraction) under the mechanical agitation provided by a vortex shaker for $1 \mathrm{~min}$ at $3800 \mathrm{rpm}$ (maximum value). Each tube was agitated individually.

\section{Official method for the analysis of inorganic fertilizer}

The official method for the analyses of inorganic fertilizers established by ANDA recommends a mass range from 0.5 to $2.0 \mathrm{~g}$ of sample. In this work, $1.0 \mathrm{~g}$ of fertilizer was treated with $10 \mathrm{~mL}$ of concentrated $\mathrm{HCl}$ and $2.5 \mathrm{~mL}$ of concentrated $\mathrm{HNO}_{3}$ and the mixture was heated in hot plate until near dryness. After that, $20 \mathrm{~mL}$ of a 1:5 (v/v) $\mathrm{HCl}$ solution was added and let it boil for a few seconds. The final solution was filtered using medium porosity paper and adequately diluted with deionized water. The time of sample preparation was around $1 \mathrm{~h}$. The final solutions were analyzed by FAAS.

\section{Results and Discussion}

\section{Official method for the analysis of inorganic fertilizer}

The three commercial samples of inorganic fertilizers were analyzed by FAAS following the sample preparation established by the official method. The two certified samples identified as 13A (year 2009) and 41A (year 2009), which correspond to sample 4 and 5, respectively, were analyzed by the inter-laboratory program of ANDA following the official method $(\mathrm{n}=33$ for $\mathrm{Cu}, \mathrm{n}=22$ for $\mathrm{Pb}$ and $n=19$ for $\mathrm{Cd}$ ). The concentration of copper, lead and cadmium in the samples are presented in Table 2.

Table 2. Concentrations of cadmium, copper and lead obtained by the official method for the analyses of inorganic fertilizers $(n=3)$

\begin{tabular}{lccc}
\hline Sample & $\mathrm{Cu} /(\% \mathrm{~m} / \mathrm{m})$ & $\mathrm{Pb} /\left(\mathrm{mg} \mathrm{kg}^{-1}\right)$ & $\mathrm{Cd} /\left(\mathrm{mg} \mathrm{kg}^{-1}\right)$ \\
\hline 1 & $0.21 \pm 0.02$ & $321 \pm 10$ & $3.1 \pm 0.2$ \\
2 & $0.36 \pm 0.03$ & $185 \pm 4$ & $31.0 \pm 0.9$ \\
3 & $0.07 \pm 0.02$ & $119 \pm 8$ & $6.20 \pm 0.04$ \\
$4^{\mathrm{a}}$ & $13.1 \pm 0.4$ & $2888 \pm 139$ & $7.7 \pm 0.9$ \\
$5^{\mathrm{a}}$ & $15.2 \pm 0.4$ & $1738 \pm 90$ & $149 \pm 11$ \\
\hline
\end{tabular}

aReference samples provided by the inter-laboratory program of ANDA.

The five inorganic fertilizer samples presented variable concentration profiles of $\mathrm{Cd}, \mathrm{Cu}$ and $\mathrm{Pb}$. These samples were used to evaluate the best conditions for the acid US-assisted extractions. The concentration values in Table 2 were considered as the total content of each metal.

\section{Ultrasound-assisted extraction}

To our knowledge, there are no reports of the application of US-assisted extractions of metals from inorganic fertilizers. However, US-assisted extractions have been applied to accelerate acid extractions of soils and sediments, which present similar sample matrix. ${ }^{16-19}$ The typical sample mass used in these works varied from 20 to $500 \mathrm{mg}$ employing diluted nitric or hydrochloric acid solutions as extractors and sonication times no longer than $60 \mathrm{~min}$. Based on this, initial tests were performed using $100 \mathrm{mg}$ of sample treated either with $\mathrm{HNO}_{3}$ or $\mathrm{HCl}$ solutions of different concentrations and sonication times of 5,10 and $30 \mathrm{~min}$.

The use of $3 \%(\mathrm{v} / \mathrm{v}) \mathrm{HNO}_{3}$ (or $3 \%(\mathrm{v} / \mathrm{v}) \mathrm{HCl}$ ) was not effective to extract the metals properly in all samples. For some samples, recovery values (considering as $100 \%$ the data in Table 2) were not higher than $20 \%$ applying $5 \mathrm{~min}$ of sonication. The application of longer sonication times (10 and $30 \mathrm{~min}$ ) did not produce significant improvement on the efficiency of metal extraction. However, the acid concentration increase produced substantial recovery values (higher than $80 \%$ ) for metal extraction employing 5 min of sonication. Figure 1 presents the effect of $\mathrm{HNO}_{3}$ concentration on the extraction of $\mathrm{Cu}, \mathrm{Pb}$ and $\mathrm{Cd}$ from $100 \mathrm{mg}$ of an inorganic fertilizer sample sonicated for $5 \mathrm{~min}$.

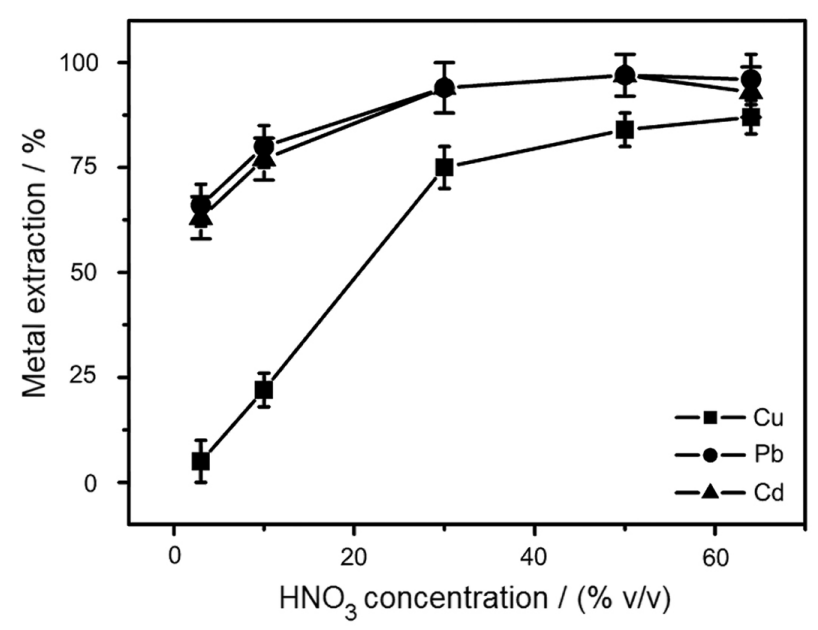

Figure 1. The effect of the $\mathrm{HNO}_{3}$ concentration on the extraction of cadmium, copper and lead from $100 \mathrm{mg}$ of an inorganic fertilizer sample sonicated for $5 \min (n=3)$.

The $\mathrm{HNO}_{3}$ concentration strongly affects metal extraction from inorganic fertilizers as shown in Figure 1. The extraction of $\mathrm{Cd}$ and $\mathrm{Pb}$ presented similar behavior with 
acid concentration increase. The use of $30 \%(\mathrm{v} / \mathrm{v}) \mathrm{HNO}_{3}$ provided efficient extraction of $\mathrm{Cd}$ and $\mathrm{Pb}$ using 5 min of sonication for $100 \mathrm{mg}$ of sample, while the extraction of $\mathrm{Cu}$ was only attained using $50 \%(\mathrm{v} / \mathrm{v}) \mathrm{HNO}_{3}(84 \%$ extraction). The use of more concentrated acid did not offer significant improvement on the efficiency of the metal extraction. Similar behavior was verified for the treatment of other fertilizer samples and for the use of $\mathrm{HCl}$ solutions as extractors. Based on these results, the acid concentration was kept at $50 \%(\mathrm{v} / \mathrm{v})$.

The sample mass was also studied for the development of the US-assisted extraction of $\mathrm{Cu}, \mathrm{Pb}$ and $\mathrm{Cd}$ in order to evaluate the adequate sample mass required for analysis without affecting sample representativity. Different amounts $(30,70,100$ and $200 \mathrm{mg}$ ) of sample were treated with $50 \%(\mathrm{v} / \mathrm{v}) \mathrm{HNO}_{3}$ and sonicated for $5 \mathrm{~min}$ in triplicate. Recovery values were satisfactory (close to $100 \%$ extraction) for US-assisted extraction of the three metals. The coefficients of variation values $(\mathrm{CV})$ for triplicate analysis were estimated in each case and the lowest value was found for $70 \mathrm{mg}$ of sample. In this way, the sample mass of $70 \mathrm{mg}$ was selected for further US-assisted extractions.

Five different inorganic fertilizer samples were analyzed by FAAS after the US-assisted extraction procedure: $70 \mathrm{mg}$ of sample was treated either with $50 \%(\mathrm{v} / \mathrm{v}) \mathrm{HNO}_{3}$ or $50 \%(\mathrm{v} / \mathrm{v}) \mathrm{HCl}$ under $5 \mathrm{~min}$ of sonication in ultrasonic bath. Table 3 presents the concentration of $\mathrm{Cu}, \mathrm{Pb}$ and $\mathrm{Cd}$ in the analyzed samples and the respective recovery values (recoveries were calculated considering as $100 \%$ the concentration values presented in Table 2).

The results shown in Table 3 attest the great performance of US-assisted extraction of $\mathrm{Cu}, \mathrm{Pb}$ and $\mathrm{Cd}$ in different inorganic fertilizer samples employing either $50 \%(\mathrm{v} / \mathrm{v}) \mathrm{HNO}_{3}$ or $50 \%$ (v/v) $\mathrm{HCl}$. Recovery values were around $100 \%$ for almost all samples. Slightly better performance was verified when samples were treated with $\mathrm{HNO}_{3}$. The extractions of $\mathrm{Cu}$ in samples 3 and 4 and of $\mathrm{Cd}$ in sample 3 were the most affected by the acid composition (superior performance for $\mathrm{HNO}_{3}$ ). The extraction of $\mathrm{Cd}$ and $\mathrm{Pb}$ in the samples 1 and 3 using $\mathrm{HNO}_{3}$, respectively, was considerably higher in comparison with the official method of analysis of inorganic fertilizer (recovery of 126 and $138 \%$ ). This result may be an indicative of superior performance of the proposed US-assisted extraction procedure, specifically for the extraction of $\mathrm{Cd}$ and $\mathrm{Pb}$ in the samples 1 and 3, respectively. On the other hand, interference from the sample matrix may be a reasonable explanation for such results.

Therefore, recovery tests were performed in order to check possible interference from the sample matrix during FAAS determinations, specifically for the analysis of samples 1 and 3. The acid extracts were spiked with different concentrations of metals in such a way that the final concentration was suitable to be determined using the respective calibration curve. Recovery values in the range of $93-103 \%(n=3)$ were obtained for the determination of $\mathrm{Cu}, \mathrm{Pb}$ and $\mathrm{Cd}$ in both samples. In this way, it is possible to assume that no interferences from sample matrix were verified for the FAAS determinations of the acid extracts.

\section{Vortex-assisted extraction}

In order to evaluate the real effect of the ultrasonic bath over metal extraction from fertilizers, the samples were similarly acid-treated (using the best conditions found for the US-assisted extraction) under the mechanical agitation provided by a vortex shaker for $1 \mathrm{~min}$. Table 4 shows the concentration of $\mathrm{Cu}, \mathrm{Pb}$ and $\mathrm{Cd}$ in inorganic fertilizer samples obtained by FAAS after vortex-assisted extraction and the respective recovery values (recoveries were calculated considering as $100 \%$ the concentration values of Table 2).

The use of vortex shaker instead ultrasonic bath for metal extraction of inorganic fertilizers is completely feasible. Recovery values for $\mathrm{Cu}, \mathrm{Pb}$ and $\mathrm{Cd}$ were around $100 \%$ for almost all the samples. The lowest extraction

Table 3. Concentrations of cadmium, copper and lead in inorganic fertilizers after US-assisted extraction procedure and respective recoveries

\begin{tabular}{|c|c|c|c|c|c|c|c|c|c|c|c|c|}
\hline \multirow{3}{*}{ Sample } & \multicolumn{6}{|c|}{$\mathrm{HNO}_{3}$} & \multicolumn{6}{|c|}{$\mathrm{HCl}$} \\
\hline & \multicolumn{3}{|c|}{$\begin{array}{c}\text { Concentration / } \\
(\% \mathrm{~m} / \mathrm{m})^{\mathrm{A}} \text { or }\left(\mathrm{mg} \mathrm{kg}^{-1}\right)^{\mathrm{B}}\end{array}$} & \multicolumn{3}{|c|}{ Recovery / \% } & \multicolumn{3}{|c|}{$\begin{array}{c}\text { Concentration / } \\
\left(\% \mathrm{~m} / \mathrm{m}^{\mathrm{A}} \text { or }\left(\mathrm{mg} \mathrm{kg}^{-1}\right)^{\mathrm{B}}\right.\end{array}$} & \multicolumn{3}{|c|}{ Recovery / \% } \\
\hline & $\mathrm{Cu}^{\mathrm{A}}$ & $\mathrm{Pb}^{\mathrm{B}}$ & $\mathrm{Cd}^{\mathrm{B}}$ & $\mathrm{Cu}$ & $\mathrm{Pb}$ & $\mathrm{Cd}$ & $\mathrm{Cu}^{\mathrm{A}}$ & $\mathrm{Pb}^{\mathrm{B}}$ & $\mathrm{Cd}^{\mathrm{B}}$ & $\mathrm{Cu}$ & $\mathrm{Pb}$ & $\mathrm{Cd}$ \\
\hline 1 & $0.24 \pm 0.01$ & $309 \pm 11$ & $3.9 \pm 0.2$ & $112 \pm 3$ & $96 \pm 4$ & $126 \pm 6$ & $0.21 \pm 0.01$ & $306 \pm 13$ & $2.8 \pm 0.2$ & $100 \pm 2$ & $95 \pm 4$ & $90 \pm 6$ \\
\hline 2 & $0.36 \pm 0.04$ & $180 \pm 11$ & $30.9 \pm 0.1$ & $100 \pm 11$ & $97 \pm 6$ & $100 \pm 1$ & $0.37 \pm 0.02$ & $175 \pm 4$ & $29.0 \pm 0.7$ & $103 \pm 6$ & $95 \pm 2$ & $94 \pm 2$ \\
\hline 3 & $0.064 \pm 0.002$ & $164 \pm 4$ & $6.1 \pm 0.1$ & $89 \pm 3$ & $138 \pm 3$ & $98 \pm 1$ & $0.050 \pm 0.002$ & $133 \pm 9$ & $4.4 \pm 0.1$ & $71 \pm 3$ & $112 \pm 8$ & $71 \pm 2$ \\
\hline $4^{\mathrm{a}}$ & $10.7 \pm 0.4$ & $2911 \pm 35$ & $8.0 \pm 0.2$ & $82 \pm 3$ & $101 \pm 5$ & $104 \pm 3$ & $8.0 \pm 0.5$ & $2652 \pm 48$ & $7.2 \pm 0.4$ & $61 \pm 4$ & $92 \pm 2$ & $94 \pm 5$ \\
\hline $5^{\mathrm{a}}$ & $14.2 \pm 0.6$ & $1331 \pm 25$ & $121 \pm 5$ & $93 \pm 5$ & $77 \pm 5$ & $81 \pm 3$ & $15.3 \pm 0.3$ & $1407 \pm 54$ & $121 \pm 9$ & $100 \pm 2$ & $81 \pm 3$ & $81 \pm 6$ \\
\hline
\end{tabular}

${ }^{a}$ Reference samples provided by the inter-laboratory program of ANDA. 
Table 4. Concentrations of cadmium, copper and lead in inorganic fertilizers after vortex-assisted extraction procedure and respective recoveries

\begin{tabular}{|c|c|c|c|c|c|c|c|c|c|c|c|c|}
\hline \multirow{3}{*}{ Sample } & \multicolumn{6}{|c|}{$\mathrm{HNO}_{3}$} & \multicolumn{6}{|c|}{$\mathrm{HCl}$} \\
\hline & \multicolumn{3}{|c|}{$\begin{array}{c}\text { Concentration / } \\
(\% \mathrm{~m} / \mathrm{m})^{\mathrm{A}} \text { or }\left(\mathrm{mg} \mathrm{kg}^{-1}\right)^{\mathrm{B}}\end{array}$} & \multicolumn{3}{|c|}{ Recovery / \% } & \multicolumn{3}{|c|}{$\begin{array}{c}\text { Concentration / } \\
(\% \mathrm{~m} / \mathrm{m})^{\mathrm{A}} \text { or }\left(\mathrm{mg} \mathrm{kg}^{-1}\right)^{\mathrm{B}}\end{array}$} & \multicolumn{3}{|c|}{ Recovery / \% } \\
\hline & $\mathrm{Cu}^{\mathrm{A}}$ & $\mathrm{Pb}^{\mathrm{B}}$ & $\mathrm{Cd}^{\mathrm{B}}$ & $\mathrm{Cu}$ & $\mathrm{Pb}$ & $\mathrm{Cd}$ & $\mathrm{Cu}^{\mathrm{A}}$ & $\mathrm{Pb}^{\mathrm{B}}$ & $\mathrm{Cd}^{\mathrm{B}}$ & $\mathrm{Cu}$ & $\mathrm{Pb}$ & $\mathrm{Cd}$ \\
\hline 1 & $0.22 \pm 0.02$ & $300 \pm 2$ & $3.8 \pm 0.2$ & $105 \pm 14$ & $94 \pm 1$ & $123 \pm 6$ & $0.22 \pm 0.02$ & $300 \pm 32$ & $2.86 \pm 0.14$ & $105 \pm 14$ & $94 \pm 10$ & $92 \pm 4$ \\
\hline 2 & $0.39 \pm 0.02$ & $179 \pm 18$ & $30.2 \pm 0.2$ & $108 \pm 6$ & $97 \pm 10$ & $97 \pm 1$ & $0.39 \pm 0.04$ & $188 \pm 13$ & $29.3 \pm 0.3$ & $108 \pm 11$ & $102 \pm 7$ & $94 \pm 1$ \\
\hline 3 & $0.054 \pm 0.005$ & $157 \pm 12$ & $5.6 \pm 0.4$ & $77 \pm 7$ & $132 \pm 10$ & $90 \pm 6$ & $0.066 \pm 0.004$ & $138 \pm 6$ & $4.1 \pm 0.2$ & $94 \pm 6$ & $116 \pm 5$ & $66 \pm 3$ \\
\hline $4^{\mathrm{a}}$ & $10.7 \pm 0.3$ & $2638 \pm 86$ & $7.8 \pm 0.2$ & $82 \pm 2$ & $91 \pm 3$ & $101 \pm 3$ & $9.5 \pm 0.8$ & $2552 \pm 141$ & $17.24 \pm 0.08$ & $73 \pm 6$ & $88 \pm 5$ & $94 \pm 1$ \\
\hline $5^{\mathrm{a}}$ & $15.0 \pm 1.1$ & $1409 \pm 115$ & $121 \pm 5$ & $99 \pm 8$ & $81 \pm 7$ & $81 \pm 4$ & $15.6 \pm 1.4$ & $1538 \pm 97$ & $118 \pm 5$ & $102 \pm 9$ & $88 \pm 6$ & $79 \pm 3$ \\
\hline
\end{tabular}

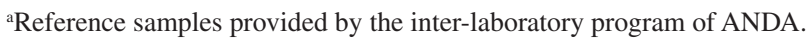

efficiencies corresponded to the same cases (sample/analyte) verified for the US-assisted extraction (Table 3). These results confirm the similar performance of a vortex shaker and an ultrasonic bath for metal extraction procedures. Therefore, it is not confirmed the presence of additional benefits (beyond mechanical agitation) exclusively provided by sonication (such as sonolysis of water which may generate hydroxyl and hydrogen peroxide $)^{10}$ which would contribute for the improvement of extraction performance. Such benefits are definitively more pronounced when ultrasonic horns are employed.

The vortex shaker used in this work for metal extraction only allowed the individual sample treatment (equipped with a head for one single tube). However, there are commercially-available vortex shakers which can treat dozens of samples at once similarly to an ultrasonic bath. Hence, the use of such vortex shakers is very promising for metal extractions of inorganic fertilizers but requires optimization for this new configuration in order to reach the similar performance obtained for US-assisted extractions using ultrasonic bath.

\section{Conclusions}

The application of US-assisted extraction for the determination of $\mathrm{Cu}, \mathrm{Pb}$ and $\mathrm{Cd}$ in inorganic fertilizers was successfully accomplished. It is important to emphasize that the analyzed inorganic fertilizer samples presented variable matrix and the content of each metal was situated at different concentration ranges in each sample. Moreover, the proposed extraction procedure is less time-consuming and generates minimal waste (reduced amounts of sample and acid are employed) in comparison with the official method of analyses of inorganic fertilizers, and hence achieves the "green" principles of analytical chemistry. The use of ultrasonic baths for sample preparation increased the sample throughput which is essential for routine purposes. A vortex shaker was also suitable for metal extraction from inorganic fertilizers and the possible use of vortex equipment capable of treat dozens of sample at once can be very promising. The proposed protocol of sample preparation can be extended for the extraction of other elements, especially volatile species, since room temperature and atmospheric pressure conditions are employed.

\section{Acknowledgements}

The authors are grateful to Labfert Análises Ltda for providing the inorganic fertilizer samples. This work was supported with grants from Conselho Nacional de Desenvolvimento Científico e Tecnológico (CNPq, 476667/2008-9), Fundação de Amparo à Pesquisa do Estado de Minas Gerais (FAPEMIG, CEX-APQ-02276-09) and Coordenação de Aperfeiçoamento de Pessoal de Nível Superior (CAPES).

\section{References}

1. Duruibe, J. O.; Ogwuegbu, M. O. C.; Egwurugwu, J. N; Int. J. Phys. Sci. 2007, 2, 112.

2. Webpage of the Brazilian Ministry of Agriculture (Ministério de Agricultura, Pecuária e Abastecimento, MAPA), http://extranet. agricultura.gov.br/sislegis-consulta/consultarLegislacao. do?operacao=visualizar\&id=5473 accessed in April 2011.

3. De Oliveira, E.; J. Braz. Chem. Soc. 2003, 14, 174.

4. Munoz, R. A. A.; Correia, P. R. M.; Nascimento, A. N.; Silva, C. S.; Oliveira, P. V.; Angnes, L.; Energy Fuels 2007, 21, 295.

5. Augelli, M. A.; Munoz, R. A. A.; Richter, E. M.; Cantagallo, M. I.; Angnes, L.; Food Chem. 2007, 101, 579.

6. Munoz, R. A. A.; Silva, C. S.; Correia, P. R. M.; Oliveira, P. V.; Angnes, L.; Microchim. Acta 2005, 149, 199.

7. Luque-Garcia, J. L.; de Castro, M. D. L.; TrAC, Trends Anal. Chem. 2003, 22, 90. 
8. Munoz, R. A. A.; Kolbe, M.; Siloto, R. C.; Oliveira, P. V.; Angnes, L.; J. Braz. Chem. Soc. 2007, 18, 410.

9. Junior, D. S.; Krug, F. J.; Pereira, M. D.; Korn, M.; Appl. Spectrosc. Rev. 2006, 41, 305.

10. Munoz, R. A. A.; Felix, F. S.; Augelli, M. A.; Pavesi, T.; Angnes, L.; Anal. Chim. Acta 2006, 571, 93.

11. Azouzi, H. E., Cervera, M. L., De La Guardia, M.; J. Anal. Atom. Spectrom. 1998, 13, 533.

12. Nascentes, C. C., Korn, M., Arruda, M. A. Z.; Microchem. J. 2001, 69, 37.

13. Koel, M.; Kaljurand, M.; Pure Appl. Chem. 2006, 78, 1993.

14. Munoz, R. A. A.; Oliveira, P. V.; Angnes L.; Talanta 2006, 68 , 850 .
15. Nascentes, C. C.; Korn, M.; Sousa, C. S.; Arruda, M. A. Z.; J. Braz. Chem. Soc. 2001, 12, 57.

16. Al-Merey, R.; Al-Masri, M. S., Bozou, R.; Anal. Chim. Acta 2002, 452, 143.

17. Hatje, V.; Costa, L. M.; Korn, M. G. A.; Cotrima, G.; J. Braz. Chem. Soc. 2009, 20, 846.

18. Marin, A.; Lopez-Gonzalez, A.; Barbas, C.; Anal. Chim. Acta 2001, 442, 305.

19. Chmilenko, F. A.; Smityuk, N. M.; Baklanov, A. N.; J. Anal. Chem. 2002, 57, 313.
Submitted: February 15, 2011

Published online: May 3, 2011 